\title{
Uma análise sobre questões de gênero nos cursos de Computação do município de Alegrete/RS
}

\author{
Aline Vieira de Mello $^{1}$, Amanda Meincke Melo ${ }^{1}$, Isadora Garcia Ferrão ${ }^{1}$ \\ ${ }^{1}$ Universidade Federal do Pampa (UNIPAMPA) \\ Av. Tiaraju, 810 - 97546-550 - Alegrete - RS - Brazil \\ \{alinemello, amandamelo\}@unipampa.edu.br, isadoraferrao9@gmail.com
}

\begin{abstract}
In Brazil, only 14\% of women enrolled in computing undergraduate degree programs conclude it. For reducing the percentage of women's drop out, it is necessary first to identify their causes. This paper has as its main objective to present the results obtained through the application of questionnaires containing questions about gender to students and teachers of the Computing undergraduate degree programs in Alegrete city. In addition to the stereotypes created since childhood, bad comments, chauvinism and the work devaluation of the women undergraduates were enunciated as difficulties, being able to contribute to women drop out.
\end{abstract}

Resumo. No Brasil, somente 14\% do número de mulheres que se matriculam em cursos da área da Computação o concluem. Para reduzir o percentual de de evasão das mulheres, é necessário primeiramente identificar suas causas. Este artigo tem como objetivo principal apresentar os resultados obtidos através da aplicação de questionários contendo perguntas sobre gênero a discentes e docentes dos cursos de Computação do município de Alegrete. Além dos estereótipos criados desde a infância, comentários ruins, machismo e a desvalorização do trabalho das graduandas foram enunciados como dificuldades, podendo contribuir para a evasão de mulheres.

\section{Introdução}

As estatísticas da Educação Superior da área de Computação [SBC 2017] indicam que, a partir de 2011, apenas 14\% do número de mulheres que se matriculam em cursos da área da Computação os concluem. Segundo [Gomes et al. 2014], é necessário compreender os fatores que levam mulheres a entrarem e a saírem de cursos na área da Computação, a fim de que estratégias adequadas sejam propostas.

Ao analisar os anais do Women in Information Technology (WIT) dos últimos três anos (2016 a 2018), identificaram-se pesquisas destinadas a entender os fatores que fazem com que meninas escolham (ou não) ingressar nos cursos da área da Computação [Aires et al. 2018][Macedo et al. 2018][Figueiredo et al. 2017][Holanda et al. 2017] [Santos et al. 2017], além de trabalhos que apresentam dados de ingresso e de evasão de mulheres nos cursos da área [Nakamura et al. 2017] [Sales et al. 2017] ou que analisam o perfil das graduandas utilizando como indicadores a situação da matrícula, a faixa etária, a procedência escolar e a renda familiar [Monteiro et al. 2017]. Dentre os trabalhos identificados, [Brum et al. 2018] é o que melhor se aproxima da proposta deste trabalho ao aplicar questionários a alunos e ex-alunos de diferentes universidades com o intuito de 
identificar sua percepção quanto às diferenças existentes entre homens e mulheres no mercado de trabalho e na universidade.

Desde 2016, a ação de extensão Gurias na Computação, vinculada ao programa de extensão Programa C - Comunidade, Computação, Cultura, Comunicação, Ciência, Cidadania, Criatividade, Colaboração - e parceira do programa Meninas Digitais, tem sido desenvolvida no Campus Alegrete da Universidade Federal do Pampa, proporcionando às acadêmicas dos cursos de Ciência da Computação e Engenharia de Software espaços de escutas e trocas de experiências. Essas estudantes universitárias também têm sido envolvidas em ações de divulgação da área a meninas da Educação Básica.

Durante encontros organizados no contexto dessa ação de extensão, pôde-se escutar as graduandas e perceber sua inquietação com comentários sexistas, com reflexos em sua autoestima. Discutiram-se, assim, propostas para abordar e compreender o sexismo no ambiente universitário, em especial no contexto dos cursos da área da Computação. Entre as propostas discutidas, estava a elaboração de questionários com questões relacionadas a gênero para serem respondidas por docentes e discentes de ambos os sexos, vinculados a instituições locais que ofertam curso superior na área de Computação. A aplicação desses questionários tiveram como principal objetivo provocar a reflexão da comunidade acadêmica quanto às questões de gênero no ambiente universitário.

Nesse contexto, este trabalho tem como objetivo apresentar resultados obtidos através da aplicação de questionários contendo perguntas sobre gênero a discentes e docentes dos cursos de Computação do município de Alegrete/RS. Diferentemente de [Ferrão et al. 2017], em que resultados obtidos através da aplicação do questionário aos discentes foram discutidos, no presente trabalho as respostas dos discentes são apresentadas separadas por gênero e comparadas às respostas dos docentes, resultando em uma análise diferenciada e, portanto, inédita. O restante do texto está organizado como segue. A Seção 2 descreve a metodologia adotada. A Seção 3 apresenta os resultados e discussões. Por fim, a Seção 4 apresenta as considerações finais.

\section{Metodologia}

Em 2017, a equipe executora da ação de extensão Gurias na Computação, composta por sete discentes e três docentes dos cursos de Ciência da Computação e Engenharia de Software da Universidade Federal do Pampa, elaborou, em reuniões periódicas e de forma colaborativa, dois questionários: um voltado aos discentes e outro aos docentes.

Além de perguntas de identificação obrigatórias (curso, instituição, sexo), o questionário voltado aos discentes possuía dez perguntas não obrigatórias, enquanto o questionário destinado aos docentes possuía sete perguntas não obrigatórias. Neste artigo são apresentadas e discutidas as quatro perguntas presentes em ambos os questionários (Tabela 1). Os questionários podem ser acessados na sua íntegra em https : / bit. Iy/ 2Y2eHpp.

No questionário destinado aos docentes, essas quatro perguntas eram do tipo Resposta Longa, ou seja, permitiam que o respondente redigisse sua própria resposta. No questionário para os discentes, as perguntas 2, 3 e 4 também eram do tipo Resposta Longa, mas a pergunta 1 era do tipo Caixa de Seleção, onde o respondente pôde escolher uma ou mais das respostas disponíveis, ou mesmo optar por redigir a sua própria resposta (opção outro). 


Tabela 1. Perguntas comuns ao questionários aplicados aos discentes e aos
docentes.
\begin{tabular}{|l|l|}
\hline $\mathbf{N}^{\mathbf{0}}$ & Pergunta \\
\hline 1 & $\begin{array}{l}\text { Quais motivos você apontaria para o ingresso pouco expressivo de mulhe- } \\
\text { res em cursos na área da Computação? }\end{array}$ \\
\hline 2 & $\begin{array}{l}\text { Você percebe algum tipo de desigualdade, no dia a dia do campus, no tra- } \\
\text { tamento dispensado a alunas e alunos e/ou professoras ou professores? Em } \\
\text { que situações? }\end{array}$ \\
\hline 3 & $\begin{array}{l}\text { Você já ouviu ou fez comentários/piadas sexistas - que discriminam em } \\
\text { função do gênero? (Professores: Como avalia o impacto na formação dos } \\
\text { estudantes?) }\end{array}$ \\
\hline 4 & $\begin{array}{l}\text { O que você propõe para ampliar a participação de mulheres na Compu- } \\
\text { tação? }\end{array}$ \\
\hline
\end{tabular}

Ambos os questionários foram elaborados no Google Forms, sendo o link enviado através de $e$-mail para discentes e docentes dos cursos da área da Computação da Universidade Federal do Pampa e do Instituto Federal Farroupilha. Nos dias 9 e 10 de maio, foi realizado um teste piloto do questionário destinado aos discentes, com a participação de 13 alunas e 12 alunos. Os questionários foram respondidos entre os dias 11 de maio e 02 de junho de 2017.

A análise das respostas aos questionários, considerando as categorias discente e docente, foram apresentadas no III Encontro Gurias na Computação e em reunião das Comissões dos Cursos de Computação da Universidade Federal do Pampa. A partir das discussões geradas, decidiu-se também analisar as respostas considerando o sexo dos respondentes.

\section{Resultados}

O questionário foi respondido por 83 discentes, sendo 51 homens $(61,45 \%)$ e 32 mulheres $(38,55 \%)$. Já o questionário direcionado aos docentes obteve 21 respostas, sendo 15 de homens $(71,43 \%)$ e 6 de mulheres $(28,57 \%)$. Como as perguntas dos questionários não eram obrigatórias, o número de respondentes é apresentado antes da análise de suas respostas, separados por categoria e sexo .

A primeira pergunta questionava sobre os motivos para o ingresso pouco expressivo de mulheres em cursos na área da Computação. Essa pergunta foi respondida por 32 alunas, 51 alunos, 6 professoras e 15 professores. Entretanto, cada respondente pôde indicar mais de um motivo. A resposta mais citada tanto por discentes quanto por docentes de ambos os sexos foi "estereótipos criados desde a infância". Para as alunas e os alunos, outro fator que contribui é a falta de divulgação dos cursos e de protagonistas mulheres. Já a falta de identificação das mulheres com o curso é a segunda causa mais citada por alunos. Ademais, dois alunos citaram que o ingresso pouco expressivo deve-se à falta de capacidade cognitiva das mulheres, indicando que ainda existe machismo mesmo entre pessoas jovens e com acesso à educação, como universitários. O gráfico, apresentado na Figura 1, compila o número de respostas para cada motivo identificado para o ingresso pouco expressivo de mulheres nos cursos de Computação, organizado por categoria.

A segunda pergunta indagava sobre a desigualdade no tratamento dispensado às 


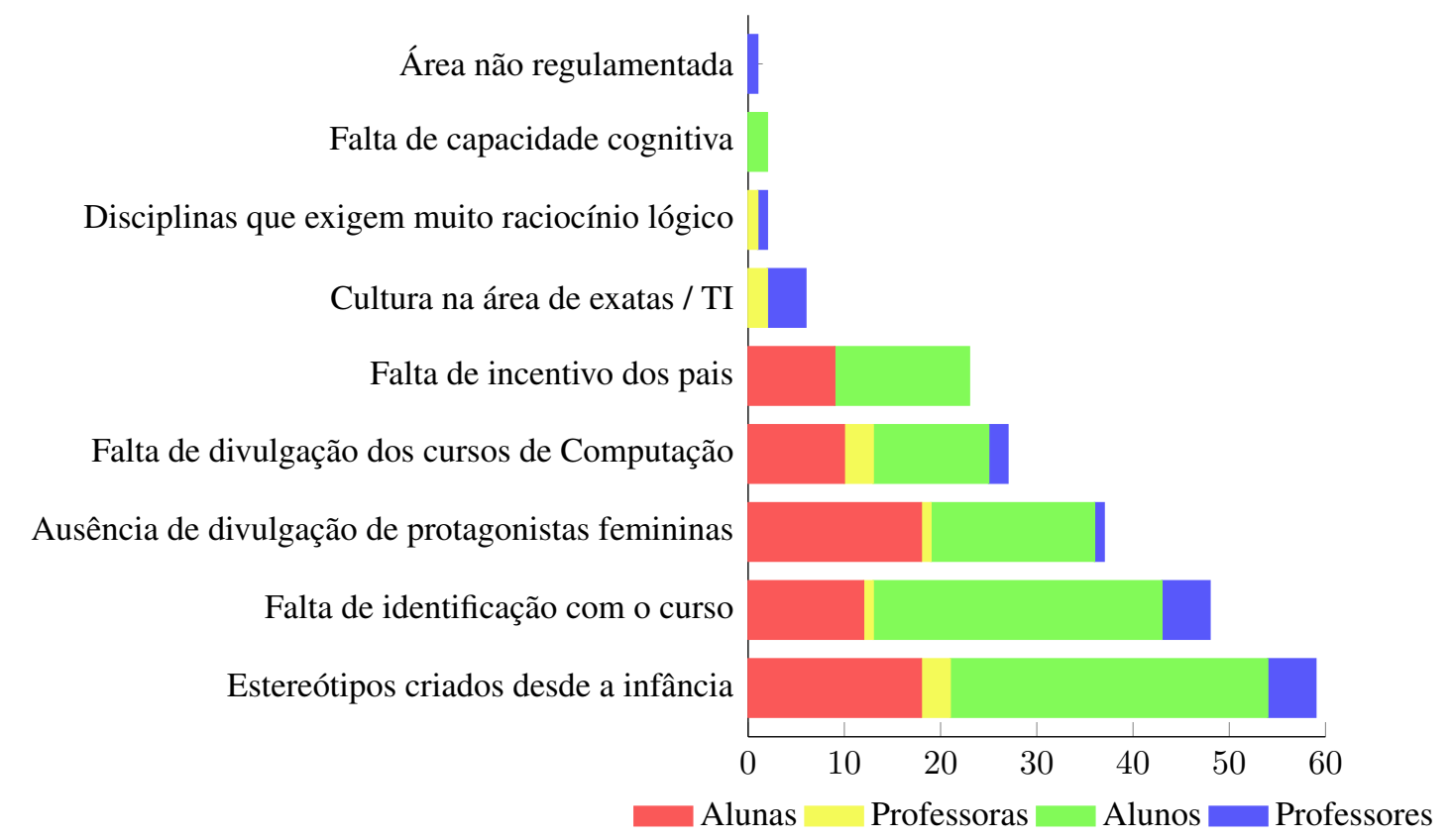

Figura 1. Motivos para o ingresso pouco expressivo de mulheres nos cursos de Computação.

alunas e aos alunos e/ou às professoras e aos professores. Essa pergunta foi respondida por 24 alunas, 47 alunos, 6 professoras e 15 professores. A Tabela 2 apresenta o número de respostas separadas por categoria. A maioria das alunas (16) e professoras (4) percebem algum tipo de desigualdade, enquanto a maioria dos alunos (35) e professores (13) não percebem desigualdades (Figura 2). Esse resultado é semelhante ao apresentado na pesquisa de Brum et al. (2018), na qual aproximadamente 50\% das universitárias que participaram da pesquisa indicaram perceber desigualdade no ambiente universitário e somente $25 \%$ dos universitários têm essa percepção.

Tabela 2. Percepção de desigualdade no tratamento dispensado a homens e a
mulheres.
\begin{tabular}{|l|l|l|l|l|l} 
& Alunas & Professoras & Alunos & Professores & Total \\
\hline Sim & 16 & 4 & 12 & 2 & 34 \\
\hline Não & 8 & 2 & 35 & 13 & 58
\end{tabular}

Alguns exemplos de situações de desigualdade mencionadas pelos discentes foram: "Professores às vezes tratam as mulheres de forma diferente, ou menosprezam o trabalho delas.", "Já percebi tratamento diferenciado para alunas esteticamente bonitas." e "Percebo. Passar sendo mulher é bem mais fácil.". Destacam-se os seguintes comentários dos docentes: "Professores tendem a perceber as meninas como mais delicadas, portanto, tratam com mais tato.", "Dificuldade em manter o foco em observações." e "No campus não, mas no mercado de trabalho há muita desigualdade, ex: salários diferentes.". Esses comentários demonstram que dentre os poucos homens que percebem desigualdades, alguns acreditam que as mulheres são beneficiadas.

Na terceira pergunta, os participantes deveriam indicar se já ouviram ou fizeram comentários/piadas sexistas na universidade, exemplificando situações. Essa pergunta 


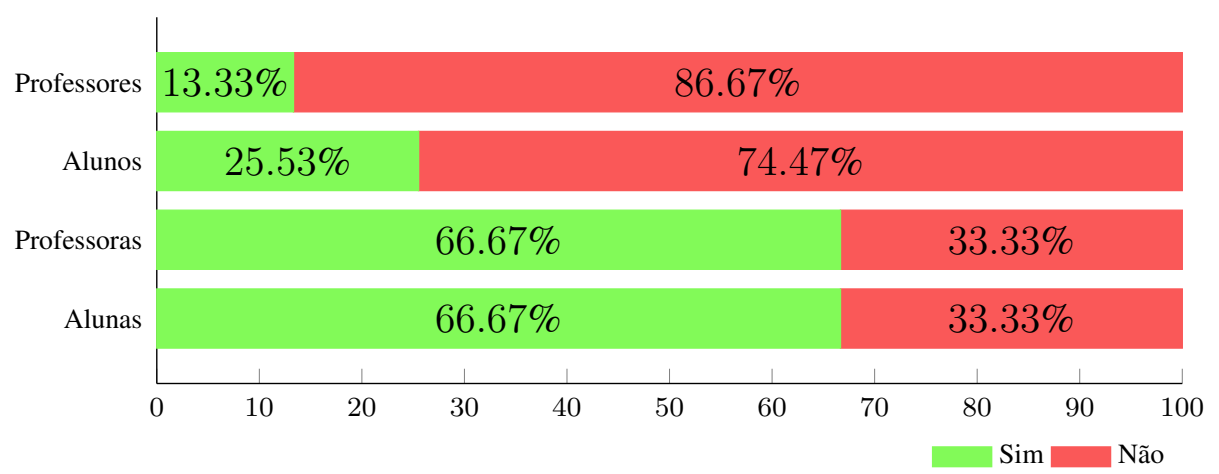

Figura 2. Percepção de desigualdade no tratamento dispensado a homens e mulheres em percentual por categoria.

foi respondida por 24 alunas, 44 alunos, 6 professoras e 15 professores. A maioria dos discentes (18 alunas e 24 alunos) e a metade das professoras (3) indicaram que já ouviram ou fizeram comentários/piadas sexistas, enquanto a maioria dos professores (10) afirmam não ter ouvido ou feito piadas (Figura 3).

Tabela 3. Número de pessoas que ouviram ou fizeram piadas sexistas

\begin{tabular}{l|l|l|l|l|l} 
& Alunas & Professoras & Alunos & Professores & Total \\
\hline Sim & 18 & 3 & 24 & 5 & 50 \\
\hline Não & 6 & 3 & 20 & 10 & 39
\end{tabular}

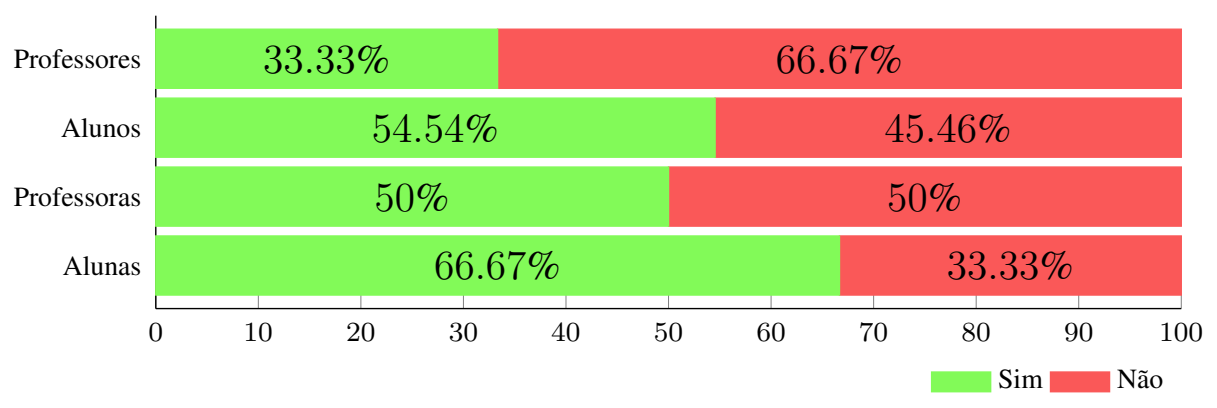

Figura 3. Percentual de pessoas que ouviram ou fizeram piadas sexistas

Dentre as piadas citadas pelos discentes, destacam-se: "Uma vez numa empresa que eu trabalhava tinha uma programadora, 'até que ela era boa'., "Lugar de mulher é na cozinha." e "Engenharia é coisa de homem.". Sobre o impacto desse tipo de comentário ou piada, algumas das percepções dos docentes: "Já presenciei comentário sexista e, acredito, que contribui ainda mais para que a área tenha uma predominância por pessoas do sexo masculino.", "Nunca fiz ou ouvi, mas já escutei histórias de ocorridos. Esses comentários desestimulam alunas que podem já estar fragilizadas pelas dificuldades tradicionais enfrentadas em cursos de Computação".

Ao comparar as respostas para as perguntas 2 e 3, constata-se que, embora apenas 12 alunos e 2 professores tenham percebido desigualdades entre os gêneros, um número maior de alunos (24) e professores (5) já ouviram ou fizeram piadas sexistas. O trabalho de [Mochetti et al. 2016] traz a seguinte reflexão de um graduando: "é preciso prestar 
atenção no machismo que a gente comete sem perceber". Essa reflexão pode explicar o motivo para o número de homens que percebem desigualdades entre os gêneros ser menor do que aqueles que já fizeram ou ouviram piadas sexistas. Ainda, a diferença de percepção sobre as desigualdades entre mulheres e homens, se não abordada e compreendida, pode contribuir à perpetuação das desigualdades existentes.

$\mathrm{Na}$ última pergunta, foram solicitadas propostas para ampliar a participação feminina na área da Computação. Essa pergunta foi respondida por 26 alunas, 41 alunos, 6 professoras e 14 professores. As sugestões mencionadas pelos discentes foram divulgar os cursos da área da Computação para estudantes da Educação Básica; realizar projetos em escolas da Educação Básica a fim de apresentar a Computação; e divulgar mulheres que fizeram contribuições significativas para a área. Alguns alunos, contudo, não percebem a necessidade de realizar ações, a exemplo de um estudante: "cada pessoa tem que buscar as informações dos cursos e escolher como bem entender". Isso sinaliza o desconhecimento de que há questões estruturais, como os estereótipos criados desde a infância, que interferem nas escolhas profissionais realizadas por homens e mulheres. Além de citar as mesmas propostas dos discentes, os docentes também propuseram tratar a discriminação de gênero no âmbito universitário. A Tabela 4 apresenta algumas propostas para ampliar a participação feminina na área de Computação.

Tabela 4. Sugestões para ampliar a participação feminina na área da Computação

\begin{tabular}{|c|c|}
\hline Categoria & Sugestão \\
\hline Aluna & $\begin{array}{l}\text { "Motivação desde cedo em escolas, tentar mostrar que exatas e } \\
\text { computação não são coisas de "sete cabeças". Que tudo com } \\
\text { dedicação e estudo é possível, muitas vezes nós pensamos que } \\
\text { não damos conta, mas no fim se estamos aqui é porque podemos } \\
\text { sim." }\end{array}$ \\
\hline Professora & $\begin{array}{l}\text { "Ampliar o debate sobre tema dentro da universidade, envol- } \\
\text { vendo alunos e professores, e assim construir mais dissemina- } \\
\text { dores de opiniões; Levar a computação para as escolas de en- } \\
\text { sino fundamental para que meninas e meninos percebam a área } \\
\text { da computação como possibilidade de formação." }\end{array}$ \\
\hline Aluno & $\begin{array}{l}\text { "Divulgação de forma mista de mulheres e homens importantes } \\
\text { envolvidos na formação da ciência e tecnologia contemporânea, } \\
\text { como Ada Lovelace, Alan Turing, Grace Hopper, Hedy Lamarr, } \\
\text { Charles Babbage, Margaret Hamilton, entre vários outros exem- } \\
\text { plos. Acredito que de forma mista mostra-se que a área independe } \\
\text { de gênero sem criar efeito bolha pra nenhum dos lados." }\end{array}$ \\
\hline Professor & $\begin{array}{l}\text { "Um paradigma que deve ser vencido é a falsa ideia de que ho- } \\
\text { mens são mais aptos nas áreas de ciências exatas do que mulheres. } \\
\text { As meninas já crescem com a falsa ideia de que nunca serão tão } \\
\text { capazes em áreas como computação, tecnologia da informação, } \\
\text { física aplicada, quanto seus colegas meninos. Acredito que o pri- } \\
\text { meiro passo seria uma conscientização já nos primeiros anos no } \\
\text { ensino fundamental, um trabalho que vise mostrar para as meni- } \\
\text { nas que elas são tão capazes quanto os meninos, e que seu gênero } \\
\text { não lhe torna menos capaz de aprender." }\end{array}$ \\
\hline
\end{tabular}


A aplicação do questionário e a divulgação de seu resultados gerou discussões bastante pertinentes entre discentes e docentes dos cursos da área da Computação, na Universidade Federal do Pampa. Alguns docentes, inclusive, reportaram que passaram a prestar mais atenção em sua conduta, especialmente relacionada à realização de piadas em sala de aula. Entretanto, algumas observações feitas por discentes e docentes sinalizam que a análise de fenômenos relacionados às questões gênero ainda merece atenção e deve continuar a ser abordada.

\section{Considerações Finais}

Os resultados indicam que, independente da categoria ou sexo do respondente, o principal fator apontado para que existam poucas mulheres em cursos da área da Computação são os estereótipos criados desde a infância. Ademais, comentários ruins, machismo e a desvalorização do trabalho das alunas, não somente por parte dos alunos, mas também por parte dos docentes, foram enunciados como dificuldades. Tais comportamentos impactam diretamente na autoestima e podem contribuir para a evasão de mulheres.

Esses resultados têm servido como base para que o programa de extensão Programa $\mathrm{C}$ organize ações junto aos docentes e graduandos de ambos os sexos a fim de minimizar o machismo e as piadas sexistas ainda recorrentes no ambiente acadêmico, zelando para que as graduandas não se sintam excluídas e concluam seus cursos. Aumentando a consciência de seu papel em relação às questões de gênero, esperamos melhorar não somente o ambiente universitário mas também, em um futuro breve, o ambiente de trabalho e a educação dos filhos desses egressos (reduzindo os estereótipos tão citados).

O desenvolvimento de ações de extensão voltadas às meninas da Educação Básica, iniciado em 2018, também deve contribuir para apresentar a Computação como uma área que se beneficia da multiplicidade das diferenças. Dado o comprometimento com a ampliação de ações relacionadas às questões de gênero, na nova edição do programa de extensão Programa C (2019-2021), essas ações estão formalizadas no projeto de extensão Gurias na Computação, que prevê entre suas ações oficinas de caráter lúdico para divulgar a Computação, o desenvolvimento de jogos que valorizem a participação feminina na área e o desenvolvimento de aplicativos destinados a minimizar problemas das mulheres da comunidade de Alegrete.

\section{Referências}

Aires, J., Mattos, G., Oliveira, C., Brito, A., Aragão, A. F., Alves, S., Coelho, T., and Moreira, G. (2018). Barreiras que impedem a opção das meninas pelas ciências exatas e computação: Percepção de alunas do ensino médio. In $12^{\circ}$ Women in Information Technology (WIT 2018). SBC.

Brum, R., Costa, R. M. E. M. d., Araújo, A. P. F., Werneck, V. M. B., and Castro, M. C. S. d. (2018). Participação de alunas nos cursos de computação na percepção de alunos e ex-alunos. In $12^{\circ}$ Women in Information Technology (WIT 2018). SBC.

Ferrão, I. G., Mello, A. V. d., and Melo, A. M. (2017). Gurias na computação: uma análise sobre questões de gênero na computação. In $9^{\circ}$ Salão Internacional de Ensino, Pesquisa e Extensão (SIEPE 2017). 
Figueiredo, K. d. S., Vitorassi, R., Monteiro, E., and Carneiro, S. d. O. (2017). Percepções de alunas de ensino médio sobre as subáreas da computação. In $11^{\circ}$ Women in Information Technology (WIT 2017). SBC.

Gomes, W. F., Louzada, C. S., Nunes, M. A. S. N., Salgueiro, E. M., and Andrade, B. T. (2014). Incentivando meninas do ensino médio à área de ciência da computação usando o scratch como ferramenta. In XX Workshop de Informática na Educação (WIE 2014).

Holanda, M. T. d., Mourão, R., Ramos, G. N., Araújo, A. P. F. d., and Walter, M. E. T. (2017). Uma pesquisa com alunas do ensino fundamental e médio sobre os cursos da Área de computação. In $11^{\circ}$ Women in Information Technology (WIT 2017). SBC.

Macedo, M. M. G., Mattos, A. B., Vasconcelos, M., Martinazzo, A., and Lopes, R. (2018). Identificando influências na escolha de uma graduação em exatas: um estudo qualitativo e comparativo de gênero. In $12^{\circ}$ Women in Information Technology (WIT 2018). SBC.

Mochetti, K., Salgado, L., Zerbinato, A. V., Souza, B. L., and Avelino, M. R. E. (2016). Ciência da computação também é coisa de menina! In $10^{\circ}$ Women in Information Technology (WIT 2016). SBC.

Monteiro, R. d. S., Marinho, J. M. P., Braga, R. B., Viana, M. d. N., and Oliveira, C. T. d. (2017). Delineando o perfil feminino discente do bacharelado em ciência da computação do ifce campus aracati. In $11^{\circ}$ Women in Information Technology (WIT 2017). SBC.

Nakamura, F., Lobo, L., Freitas, R. d., Almeida, T., Machado, A. L., and Lauschner, T. (2017). Participação feminina em cursos de computação: um estudo no instituto de computação da universidade federal do amazonas. In $11^{\circ}$ Women in Information Technology (WIT 2017). SBC.

Sales, A. S. d. S., Reis, L. S., Lima, M. D. F. C., and Silva, D. R. D. (2017). Evasão das mulheres dos cursos de computação: Um estudo de caso na paraíba. In $11^{\circ}$ Women in Information Technology (WIT 2017). SBC.

Santos, M. P., Santos, C. P., and Ellwanger, C. (2017). A computação sob a Ótica de meninas do ensino médio. In $11^{\circ}$ Women in Information Technology (WIT 2017). SBC.

SBC (2017). Educação superior em computação estatísticas 2017. http : / / www . sbc . org.br/documentos-da-sbc/category/133-estatisticas. Accessed: 2019-03-20. 